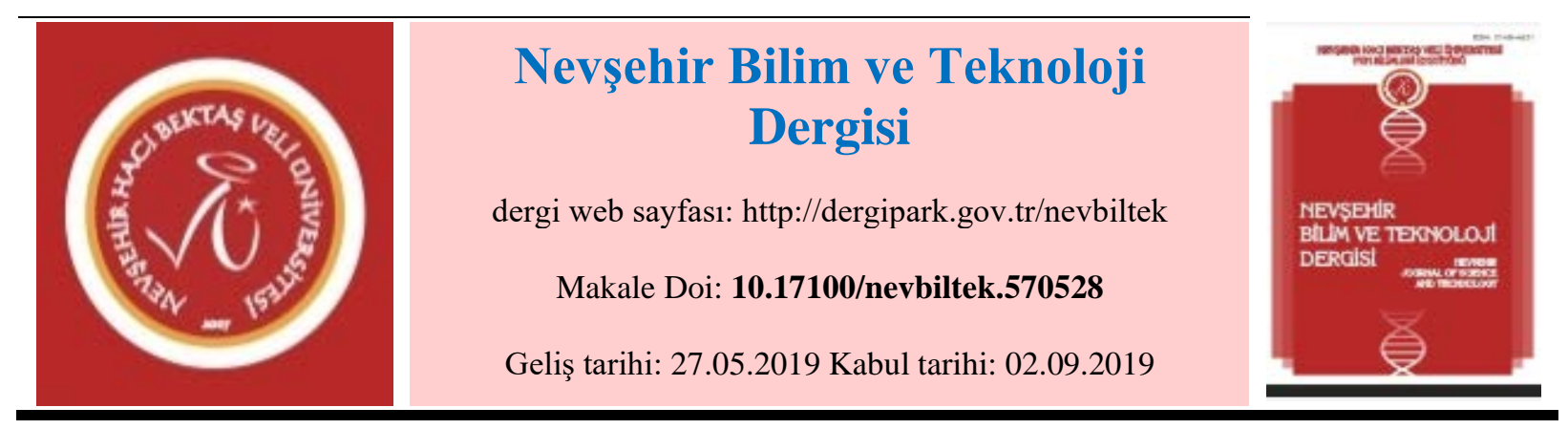

\title{
Madencilik Faaliyetleri ile Bozulmuş Arazilerin Onarımında Peyzaj Mimarlarının Rolü
}

\author{
Aslıhan ESRINGÜ̈ ${ }^{1}$, Serkan ÖZER ${ }^{2}$ \\ ${ }^{1}$ Atatürk Üniversitesi Mimarlık ve Tasarım Fakültesi, Peyzaj Mimarlığı Bölümü, Erzurum \\ ORCHID ID: 0000-0002-7930-5290 \\ ${ }^{2}$ Atatürk Üniversitesi Mimarlık ve Tasarım Fakültesi, Peyzaj Mimarlığı Bölümü, Erzurum \\ ORCHID ID: 0000-0002-1220-206X
}

\begin{abstract}
Özet
Madencilik faaliyetleri esnasında yönetmeliğe uyulmadan yapılan çalışmalar beraberinde birçok çevresel sorunu getirmektedir. Madenin çıkarılması alanda ekolojik, fiziksel, kimyasal hatta biyolojik değişikliklere neden olmaktadır. Bu durum doğal yapının bozulması olarak ifade edilmektedir. Onarım çalışmalarına, farklı meslek disiplinleri (haritalama, jeolojik, hidrojeolojik, meteorolojik, klimatolojik ve dendrolojik) yapmış oldukları planlamalar ile çözüm bulmaktadırlar. Bu meslek disiplinlerinden biri olan peyzaj mimarlarının onarımda ki rolü , tasarım ve planlanma ilkelerinde dikkat edilmesi gereken hususların ortaya konulması, canlı ve cansız materyallerin kullanılarak alanın tekrar doğaya kazandırılması gibi konularda destek olmaktadırlar. Madencilik faaliyetleri sonucu bozulmuş alanların yeniden doğaya kazandırılması ile alanların rekresyonel potansiyellerinde artış sağlanabilmektedir..
\end{abstract}

Anahtar Kelimeler: Maden alanı, Peyzaj Mimarı'nın rolü, Peyzaj onarım

\section{Role of Landscape Architects in Repair of Damaged Lands by Mining Activities} Abstract

Many environmental problems arise with the work done without obeying the legal regulations during the mining activities. The removal of the mine causes ecological, physical, chemical or even biological changes in the area. This situation is expressed as the deterioration of the natural structure. In the restoration work, different occupational disciplines (mapping, geological, hydrogeological, meteorological, climatological and dendrology) have been trying to solve the problems from their planning perspectives. The role of landscape architects, belonging to one of these professional disciplines, support to introduce the important issues in the principles of design and planning, bringing again the nature of the field using living and non-living materials. In this way, reintroduction of degraded lands to nature is ensured.

Keywords: Mining fields, The role of landscape architecture, Landscape restoration 


\section{Giriş}

Maden yerkabuğunu oluşturan jeolojik birimlerin içerisinde bulunan ve ekonomik yönden değer taşıan mineral ve elementler olarak tanımlanmaktadır. Madencilik faaliyeti ise madenlerin aranması, üretime yönelik hazırlık çalışmaları, üretilmesi, sevkiyatı, cevher hazırlama ve zenginleştirme, atıkların bertarafı, ruhsat sahasındaki stoklama/depolama işlemleri, maden işletmelerinin kapatılması ve çevre ile uyumlu hale getirilmesi ile ilgili tüm faaliyetler ve bu faaliyetlere yönelik tesislerin yapılmasını içermektedir [1]. Madencilik faaliyetleri insanlık tarihi ile başlayan en eski sektörlerden biridir. Tarihte insanlığın gelişim evrelerinde madenlerin bulunması ve işlenmeye başlanması büyük rol oynamıştır.

Madenler temelde insana doğa karşısındaki mücadelesinde çok önemli bir güç kazandıran milyonlarca yılda oluşan tüketildiğinde yenilenemeyen kaynaklardır. 1950’li yıllarda başlayan sanayi devrimi ile madenlere olan ihtiyaç artış göstermiştir. Bugün birçok alanda, kullandığımız arabalardan, içinde yaşadığımız evlere, bilgisayarlardan telefonlara kadar yaşamımız için vazgeçilmez olan hemen her şey, madencilik etkinlikleri sonucu elde edilen ürünler sayesinde varlık kazanabilmektedir. Bu nedenle insan ve toplum yaşamında vazgeçilmez önemini kavrayan ülkeler bir yandan mevcut kaynaklarını geliştirip ülke kalkınmasının hızlanmasına katkıda bulunurken diğer tarafdan sektörde arama çalışmalarını artırma çabasına girmişlerdir [2].

Dünya çapında ekonomik gelişimin belirleyicisi olan madenlerin işletilmesi ekonomiye katılması ülkelerin gelişmesi için kaçınılmaz bir durumdur. Fakat madencilik faaliyetleri esnasında doğal kaynaklarımızda ve yakın çevresinde çevre ve canlı sağlığını tehtid eden geri dönüşü mümkün olmayan tahribatlar meydana getirebilmektedir. Sahalarda ortaya çıkan bu tahribatların hafifletilmesi veya tamamen kaldırılabilmesi için madencilik faaliyetlerinin planlama aşamasından başlayıp, madencilik faaliyetleri boyunca ve madencilik sonrası alan kullanımları aşamasına kadar ekolojik, ekonomik ve estetik değerler dikkate alınarak bütüncül uygulamaları içermelidir [3]. Günümüzde maden işletmeleri madencilik faaliyetleri başlamadan önce kanunlar ve yönetmelikler gereği işletmenin kuruluşundan, üretim ve son kapanmaya kadarki tüm dönemlerinde saha düzenlemesi ile ilgili planlamalarını yapmış olmaları gerekmektedir [4].

Madencilik faaliyetleri, açık ve kapalı madencilik olmak üzere iki ana yöntemle yapılmaktadır. Cevherin yeryüzüne yakın bir tabakada bulunması durumunda açık madencilik yöntemi kullanılması gerekirken, cevherin yeryüzünün derinliklerinde bulunması hâlinde ise kapalı madencilik yöntemi kullanılır. Günümüzde dünya maden üretiminin yaklaşık \% 70'inde açık ocak maden işletmeciliği yöntemi kullanılmaktadır. Bu yöntem çevre üzerine, fauna ve floranın azalması veya tamamen ortadan kalkması, arazi topoğrafyasının değişmesi, jeolojik ve hidrojik yapının bozulması şeklinde doğrudan ciddi tahribatlar yapmaktadır. Kapalı ocak madenciliği yerin derinliklerinde bulunduğu durumlarda uygulanan bir yöntem olduğundan açık ocak maden işletmeciliği kadar tahribata yol açmamaktadır. Fakat arazi bozulmalarına neden olmaktadırlar [5]. Bu alanlarda onarım çalışmaları yapılmaz kendi haline bırakılırsa doğanın mevcut florasının eski haline gelebilmesi için asgari 40-50 senelik bir zamana ihtiyaç duyulmaktadır [6]. Kısaca madencilik faaliyetleri sonucu ortaya çıkan olumsuzluklar doğal çevrenin özelliğine, maden ocağının yapısına, uygulanan madencilik tekniğine ve işletmenin yapısına bağlı olarak kısmen farklılıklar gösterebilir [7]. 
Kapalı madencilik işletmelerin bulunduğu alanlarda peyzaj planlaması ekolojik faydalar yanında turizm için kullanıldığında alanın rekreasyon potansiyelini artırarak ekonomik ve sosyal faydaların ortaya çıkmasına katkı sağlamaktadır [8]. Kapalı madencilik alanları kendilerine özgü bir özelliğe sahiptirler. Bu alanlar sadece mimari olarak değil aynı zamanda jeolojik veya topografik yapısı ile peyzaj unsurlarını da kapsayacak şekilde turizm için de geliştirilebilirler [9].

Madencilik faaliyetlerinin çevreye olabilecek etkileri genel olarak, doğal yapının bozulması, topografyanın değişmesi, arazi kullanımının değişmesi, toz ve gaz emisyonları, katı atıklar, sıvı atıklar, tehlikeli atıklar, proses atıkları, bölgenin sosyo ekonomik yapısında değişiklikler gibi etkiler şeklinde ön plana çıkmaktadır. Türkiye jeolojik yapının bir sonucu olarak önemli sayıda maden çeşitliliğine sahip ve maden kaynakları yönünden zengin bir ülke olması nedeniyle şanslı ülkeler arasındadır. Fakat maden alanlarının çevreye vermiş oldukları etkileri ile ilgili kanun ve yönetmelikler ancak son 20 yıl içinde çıkartılabilmiştir.

Madencilik sonrası doğa onarımı ve yeniden kazanımla ilgili dünyadaki uygulamalar hayli ileri boyuttadır. Türkiye'de doğa onarımları, madencilik sonrası ortaya çıkan bir gereklilik olarak düşünülürken, gelişmiş ülkelerde madencilik faaliyetinin başlamasıyla birlikte ele alınmaktadır [10]. Maden alanlarındaki peyzaj restorasyonuna madenciliğin başlangıç aşamasında uygulanmaya başlandığında toprak örtüsü, su birikintileri, toprak ve bitki gibi çeşitli ekosistemlerin korunduğu ortaya konulmuştur [11].

Bilim ve teknolojinin gelişmesiyle, madencilik alanlarındaki zarar görmüş peyzaj alanlarının yeniden kullanılması ekolojik restorasyon için bir alternatif olabilmektedir. Kapatılmış madenler uygun planlamalarla iyileştirilebilir ve yeniden kullanılabilir hale getirilerek geri kazanılabilir [12]. Kent merkezine yakın alanlarda işletme faaliyeti tamamlanmış olan ocakların, rekreasyonel amaçlarla yeniden düzenlenmesi, arazinin geri kazanımı için tercih edilebilecek “en akılcı” yollardan birisidir. Özellikle bu alanların, rekreasyonel amaçlar için düzenlenmesi, kişilerin sosyal, fizyolojik ve psikolojik yapıları üzerine olumlu etkiler sağlamaktadır [13].

Yapılan bu çalışmanın amacı, Peyzaj Mimarlığı meslek mensuplarının madencilik faaliyetlerinin başlangıcında, devamında ve kapanış sonrasında bozulmuş arazilerin onarımında üstlerine düşen görev ve sorumlulukları araştırmaktır.

\section{Materyal ve Metot}

Çalışmanın materyalini maden alanlarının işletilmesi sonrasında mevcut alanlarda ortaya çıkan bozulmuş alanların ıslahında Peyzaj Mimarı ünvanına sahip kişilerin üstlerine düşen görevleri nedir sorusunun cevabını bulmak için yapılan literatür taramaları sonucu elde edilen veriler oluşturmaktadır. Çalışmanın metodunu ise bu konuda yapılan literatür taramaları ile elde edilen verilerin analiz, sentez ve değerlendirmesi oluşturmaktadır. 


\section{Bulgular}

\section{Peyzaj Onarım}

Çevre sorunları insanlık tarihi ile var olan bir süreçtir. Fakat aşırı nüfus artışı, sanayileşme ve hızlı kentleşmeye bağlı olarak artan kaynak kullanımı tüm canlıları tehtid edecek düzeyde çevre sorunlarının ortaya çıkmasına neden olmaktadır. Dünyada 1960'lı yıllardan sonra çevre ile ilgili konferanslar, toplantılar, raporlar, mevzuatlar ve kanunlar yapılmaya başlanmıştır. Türkiye de ise çevre konusu ilk olarak 1982 Anayasası'nın 56. maddesi ile ortaya çıkmış, 9 Ağustos 1983'de kabul edilen Çevre Kanunu'nun 28. maddesi ile de yasal olarak kanunlaşmıştır [14]. Yapılan bu çalışmalar neticesinde sürdürelebilir bir çevre için doğayı tehdit eden unsurların kaynağında yönetilmesi ve çözüm önerilerinin sunulması istenmektedir. Bu noktada birçok meslek disiplinine ihtiyaç duyulmaktadır. $\mathrm{Bu}$ meslek gruplarından biri olan Peyzaj Mimarları da peyzaj onarım süreçlerinin tüm aşamalarında görev alarak sürdürülebilir çevre konusunda destek olmaktadırlar.

Peyzaj onarımı, çeşitli kullanımlarla tahrip edilmiş alanların tahribatın bertaraf edilmesi, alanın yeniden düzeltilmesi ve alanda yeni koşulların yaratılmasını sağlayacak çalışmaların tamamını kapsayan bir iyileştirme sürecidir [15]. Özellikle açık ocak maden işletmeciliği yapılan alanlarda toprak kaybına bağlı olarak ortaya çıkan bitkisi örtüsündeki değişimler, erozyon, ekolojik dengenin ve görsel kalitenin bozulması gibi ortaya çıkan olumsuz etkiler peyzaj onarım ile iyileştirilerek bozulan sahalarda arazinin yeniden eski haline getirilmesi, doğal dengenin kurulması ve tüm canlıların güvenle faydalanabileceği bir alan yaratılması sağlanabilmektedir. Tahrip edilen bu alanları restore ederken alanın ekolojik, ekonomik ve estetik değerleri göz önünde bulundurulması gerekmektedir.

Peyzaj onarım çalışmaları 4 aşamadan meydana gelmektedir:

1- Alan kullanım planlaması: Planlama çalışmalarının ana hedefi, toplumun ve bireylerin insan onuruna yaraşır, sağlıklı, özgür, dengeli ve nitelikli yaşam koşullarına sahip olabilecekleri bir çevre yaratılmasıdır. Madencilik faaliyetlerinin yürütülmesi esnasında ve bitiminde alan kullanım planlamasının baştan belirlenmesi durumunda madencilik ve peyzaj onarım faaliyetleri beraber yürütüleceğinden para ve zaman kaybına uğranmamış olacaktır.

Madencilik faaliyetleri sonrası alanın tüm topoğrafyası, toprak özellikleri, fauna ve florası değişeceğinden çevrenin uğradığı olumsuzlukları en aza indirgeyecek uygun bir kullanım planlamasının fiziki ve sosyal sınırlayıcı faktörler, ülkesel, bölgesel, yöresel plan kararlarını dikkate alarak yapmak gerekmektedir.

Madencilik sonrası alan kullanım planlamasının aşamaları özetle aşă̆ıda verilmiştir

- Madencilik öncesi şartların envanterinin çıkarılması,

- Etkilenecek birimlerin ihtiyaç ve isteklerini karşılayacak şekilde arazinin işletme sonrası gereksinimlerinin belirlenmesi ve bu konuda karar verilmesi,

- En uygun çözüme ulaşmak için alternatif alan kullanımları ile ilgili tüm planların analizi,

- Teknik, sosyal ve ekonomik koşullara uyumlu alan kullanım planlarının geliştirilmesi. [16].

Bu bilgiler ışı̆̆ı alında alan kullanımına uygun planlamaların yapılması gerekmektedir. 
2- Yeniden düzenleme: Planlamaya uygun kazı-döküm yapılması, bitkisel toprağın ayrı olarak depolanıp daha sonra serilmesi, tesviye, drenaj ve su rejimi kontrolü ve gerekli alt yapının hazırlanması yeniden düzenleme işlerinin ana çalışma konularını içermektedir [17]. Madencilik faaliyetleri sonrasında alan üzerinde yapılacak yeniden düzenlemeler ile alan kullanım potansiyeli için sınırlayan dik eğimler azaltılabilir, zehirli atıklar gömülebilir, tohum yatağının hazırlanması kolaylaştırılır, erozyon tehlikesi azaltılır ve maden çukurları kısmen veya tamamen doldurulabilir şeklinde iyileştirilmeler sağlanabilir.

3- İyileştirme: İyileştirme faaliyetleri biyolojik verimliliğin yeniden kazandırılması için toprağın değerlendirilmesi-geliştirilmesi ile yeniden bitkilendirme çalışmalarını içermektedir. Toprağın değerlendirilmesi ve geliştirilmesi faaliyeti arazinin madencilik sonrası uygun bir verimliliğe ulaştırılması için şarttır. Uygulanacak bu faaliyet ile iyileştirme kısa sürede ve daha ekonomik olarak gerçekleştirilebilir [18].

Yeniden bitkilendirme çalışması madencilik faaliyetlerinin ilk aşamasında başlar ve toprak iyileştirme çalışmaları tamamlanır tamamlanmaz uygulamaya geçilir. Bu faaliyet alanın büyüklüğüne, alt yapı olanaklarına, toprak iklim koşullarına, ekim zamanına, tohum yatağının durumuna ve ekonomik güce bağlı olarak seçilecek ekim-dikim metodu ile yapilır.

4- İzleme ve bakım: Uygun bir yeniden düzenleme ve iyileştirme çalışmasından sonra arazinin verimli olarak kullanılmasını sağlamak için izleme ve bakım çalışmaları yapılır. Çalışmalardaki başlıca faktörler, su kalitesi, drenaj, şev duyarlılığı ve erozyon izlenmesi gibi sıralanabilir. Kalıcı bitkilendirmeyi takiben ise büyüme izlenir ve kaydedilir. Döküm alanlarında toprağın durumu ve gelişimi ise gerekli denemeler yapılarak gözlenebilir [19].

\section{Peyzaj Onarım Faaliyetlerinde Peyzaj Mimarlarının Rolü}

“16/12/2003 tarihli ve 25318 sayılı Resmî Gazete’de yayımlanan Çevresel Etki Değerlendirmesi Yönetmeliğinin ekinde yer alan Ek-I kapsamındaki “Doğaya Yeniden Kazandırma Planını bir projeyi gerçekleştirmeyi planlayan faaliyet sahipleri bu planı aynen uygulayacağını gösterir noter tasdikli taahhüdü ilgili idari mercilere sunmak ve projelerini verilen kararlara göre gerçekleştirmekle yükümlüdürler.” Yönetmelikte ele alındığı şekliyle, terkedilmiş maden alanlarının yeniden doğa ve çevreye geri kazandırmak için peyzaj mimarlarına önemli görevler düşmektedir. Bu aşamada Peyzaj Mimarına düşen, madencilik faaliyetleri öncesinde arazi özelliklerinin belirlenmesi (Fiziksel yapı, iklimsel özellikler); doğal çevrenin son alan kullanım kararlarının oluşturulması, ekolojik hedeflerin belirlenmesidir. İlgili yönetmelikte madencilik faaliyetleri nedeniyle bozulan sahaların yeniden düzenlenmesi ve iyileştirilmesi aşamalarının tamamında (Planlama, yeniden düzenleme, iyileştirme, izleme ve bakım aşamaları) Peyzaj Mimarlarının uzmanlık alanına giren çalışmalar yer aldığı görülebilmektedir.

Planlama aşamasında yönetmelik gereği, arazinin yeri; durumu; arazinin coğrafi, jeolojik, meteorolojik, sosyoekonomik, flora ve fauna özellikleri; arazinin altyapı durumu; kültürel, tarihi ve arkeolojik varlıklara dair durumu; sahadaki gürültü seviyesinin tespit edilmesi ve çevresel risk değerlendirmesi gerçekleştirilmelidir. Bu 
aşamada Peyzaj Mimarına düşen, madencilik faaliyetleri öncesinde arazi özelliklerinin belirlenmesi (Fiziksel yapı, iklimsel özellikler), doğal çevrenin son alan kullanım kararlarının oluşturulması, ekolojik hedeflerin belirlenmesidir. Bozulmuş alanların yeniden düzenleme aşaması için yönetmeliğin gerekli gördüğü çalışmalar; korunması gereken üst toprak hakkında bilgilerin elde edilmesi, toprak kaybını en aza indirgeyecek sıyırma tekniklerinin kullanılması, malzemenin taşınması, depolanması, saklanması, kazı alanlarının doldurulması ve tesviyesi, depolama alanlarının tesviyesi, yeniden düzenlenen alanlara üst toprağın geri serilmesi, su kirliliğinin önlenmesi, sahanın habibat oluşumuna uygun olarak hazırlanması gerekmektedir. Bu aşamada Peyzaj Mimarı çalışmanın planlamasının (Döküm sahalarının yeri, örtü tabakasının yayılması, kazı şekli ve araziye son şeklinin verilmesi) yapılması, alandaki doğal drenaj yapısının oluşturulması ve depolanmış üst toprağın erozyonu önlemek amacıyla bitkilendirilme yapmakla sorumludur (Çayır ve mera bitkileri ile). İyileştirme aşaması için yönetmeliğin gerekli gördüğü çalışma, bozulan tüm alanların geleceğe dönük kullanım planlaması çerçevesinde yeniden bitkilendirilmesidir. Bitkilendirme aşamasında endemik türlerin çoğaltılması, doğal türlerin seçimi teşvik edilmelidir. Bu aşamada yapılması gerekenler, arazinin bitkilendirme için hazırlanması, bölgeye ait bitkilerin tanımı ve incelenmesi, fidelerin yetiştirilmesi, malçlama, gübreleme, bitkilerin nakli, tohum ekme ve fidan ekme, ağaçlandırma, zararlı ot kontrolü için önlemlerin alınmasıdır. Bu aşamada tahrip edilmiş alana biyolojik verimliliğin yeniden kazandırılması (zehirli atıkların ve kimyasalların uzaklaştırılması) ve yeniden bitkilendirme (çayır-mera bitkileri, baklagiller, diğer otsu ağaç ve çalı tohumları) gibi faaliyetler Peyzaj Mimarlarının gözetiminde yapılmalıdır. Son aşama olan izleme ve bakım aşamasında Peyzaj Mimarı' nın yapması gerekenler, izleme çalışmaları, bitki gelişimi, su kalitesi, şev duyarlılığı ve erozyon tahribatı gibi konularıdır. Alan geri kazanım çalışmaları çok hassas bir konudur. Yapılan planlamalarda ve uygulamalarda kamu yararına hizmet edebilmesi ve en doğru şekilde kullanılması için ekolojik koşulların alanın politik, sosyolojik, ekonomik koşulları ile birlikte gözetilmesi gerekmektedir [15].

Diğer maden alanlarından biri olan taş ocağı sektörüde hızlı nüfus artışı ile hammaddeye olan talebi karşılamak için gelişmekte ve bunun sonucunda doğal denge bozulmakta ve tahribat artmaktadır [20]. Taş ocaklarıda diğer maden alanlarının ortaya çıkarmış olduğu tahribata paralellik göstermektedir. Faaliyeti bitmiş bir taş ocağı, işletmecisi tarafından terk edilip kapatılmasından sonra peyzaj mimarının bu alanı doğaya yeniden kazandırmak için yapacağı plan aşamalarını da şöyle sıralayabiliriz;

a. Faaliyet öncesi, faaliyet alanı ve çevresindeki flora, fauna tespit, toprak, su, hava, doğal ve kültürel peyzaj değerleri, jeolojik koşulları, jeomorfolojik, hidrojeolojik, jeolojik risk, sosyo-ekonomik ve kültürel faktörler dikkate alınarak mevcut durumun ortaya konması

b. Faaliyet sahasının fiziksel, kimyasal ve jeolojik duraylılığının sağlanması

c. Faaliyet sahasının yeniden düzenlenmesi

d. Toprak, su ve hava yönetimi çalışmalarının gerçekleştirilmesi

e. Peyzaj çalışmalarının gerçekleştirilmesi

f. Faaliyet alanlarının iyileştirilmesi

g. Faaliyet alanlarının kapatılması ve terk edilmesi

h. İzleme ve denetim yönetimlerinin gerçekleştirilmesi [21]. 


\section{Sonuç ve Öneriler}

16/12/2003 tarihli ve 25318 sayılı Resmî Gazete'de yayımlanan "Çevresel Etki Değerlendirmesi Yönetmeliği", 14/12/2007 tarih 26730 ve 23/01/2010 tarih 27471 sayllı çıkarılan "Madencilik Faaliyetleri İle Bozulan Arazilerin Doğaya Yeniden Kazandırılması” yönetmeliklerinde madencilik faaliyetleri nedeniyle bozulan sahaların yeniden düzenlenmesi ve iyileştirilmesi aşamalarının tamamında (Planlama, yeniden düzenleme, iyileştirme, izleme ve bakım aşamaları) Peyzaj Mimarlarının uzmanlık alanına giren ve katkı koyacağı bölümler yer aldığı görülmektedir [22-23-24]. Peyzaj mimarları peyzaj onarımı konusunda, madencilik faaliyetleri ile bozulan alanların iyileştirilmesindeki tahrip edilen alanları eski ekolojik ve ekonomik değerini geri kazandırmak görevini üstlenmişlerdir. Alanda yeniden düzenlemeleri yaparken sadece bitkilendirme ile çevreye yeşili sunmanın yanında insanların kullanımına açık, estetik ve görsel yaşam alanları sağlamak, bu yaşam alanlarını çevre ve insanlarla bütünleştirmek, yaban hayatının gelişimi ve besin zincirinin kendiliğinden sağlanması için ortam hazırlanmasına imkan sunmak, sığ hafriyat yerlerini suyla doldurulup balık yetiştirmeye uygun hale getirmek, alanda rekreasyon amaçlı eğlence ve dinlenme yerleri düzenleyerek alana ekonomik değer kazandirabilirler.

Maden alanlarının onarım aşamaların da birçok meslek disiplini birbirleri ile işbirliği içinde bulunarak ortak çözüm önerileri üretmeleri gerekmektedir. Bu meslek gruplarından biri olan Peyzaj Mimarlarına da planlama, alan kullanım tasarımı, yeniden düzenleme, iyileştirme ve izleme-bakım aşamalarının tümünde çok sayıda görev düşmektedir. Peyzaj Mimarları almış oldukları eğitimle ve kazanıkları tecrübeler ile üstlerine düşen bu görevleri yerine getirebilecek yetkinliğe sahib olmalarına rağmen bu meslek grubundaki kişilere konu ile ilgili çalışma grublarında hak ettiklerinde önem verilmemektedir.

\section{KAYNAKLAR}

[1] Maden Yönetmeliği (21 Eylül 2017) TC. Resmi Gazete (Sayı: 30187) Erişim adresi; www. resmigazete.gov.tr/eskiler/2017/09/20170921.htm

[2] Başol, K., 1996. Doğal Kaynakları Ekonomisi, Anadolu Matbaası, Gözden Geçirilmiş 4.Baskı, İzmir.

[3] Kocaman, R., Kocaman, B. 2016. Maden Sahalarında Yapılan Faaliyetlerin Çevreye Etkisi ve Rehabilitasyon Çalışmaları. ISEM 2016, 3rd International Symposium on Environment and Morality, 4-6 November 2016, Alanya - Turkey

[4] Okyay, V., Aydın, O. 2013. Madenlerde Saha Düzenlemesi (Rekültivasyon - Rehabilitasyon) Madencilik Türkiye Dergisi, 1Mart 2013

[5] www.cem.gov.tr/erozyon/ Maden Sahaları Rehabilitasyon Eylem Planı Taslağı 2014-2018

[6] Özbey, D. 2005. Açık Ocak Madenciliği Sonrası Onarım Çalışmalarında Peyzaj Mimarlarının Rolü. Madencilik ve Çevre Sempozyumu, 5-6 Mayıs 2005, Ankara

[7] Akpınar, N. 2005. Madencilik Faaliyetleri Sonrası Onarım Çalışmalarında Bitkilendirme Süreci. Madencilik ve Çevre Sempozyumu, 5-6 Mayıs 2005, Ankara

[8] Pretes, M. 2002 Touring mines and mining tourists. Annals of Tourism Research 29(2):439-456

[9] Ballesteros, E.R., Ramírez, M, H., 2007. Identity and community Reflections on the development of mining heritage tourism in Southern Spain. Tourism Management Volume 28, Issue 3, June 2007, Pages 677687 
[10] Fidan, A. 2016. Dünyada ve Türkiye'de Madencilik Faaliyetleri, Altın Madenciliği'nin Çevresel Açıdan Değerlendirilmesi. Kent Akademisi Kent Kültürü ve Yönetimi Hakemli Elektronik Dergi Cilt:9 Sayı: 2 Yaz 2016)

[11] Nicolau, J.M. 2003. Trends in relief design and construction in opencast mining reclamation. Land Degradation \& Development 14:215-226

[12] Warhurst, A., Noronha, L. 2000. Corporate strategy and viable future land use: planning for closure from the outset of mining. Natural Resources Forum 24(2):153-164

[13] Işık, Özdemir, B., Demir, S. 2015. Açık İşletme Maden Ocaklarındaki Bitkisel İyileştirme Çalışmalarının Peyzaj Mimarlığı Öğrencilerine Göre Değerlendirilmesi. İnönü University Journal of Art and Design ISSN: 1309-9876 E-ISSN: 1309-9884 Cilt/Vol. 5 Say1/No.12 (2015): 1-12

[14] TC. Resmi Gazete, 11 Ağustos 1983, sayı:18132.

[15] Güneş, Z., Gülay, E., Avgan, M., Onur, A.H., Arüv,C., Kurum, E. 2013. Peyzaj Onarım Kitabı. Peyzaj Mimarları Odası Yayınları e kitap 2013/4

[16] Ramani, R.V. 1987. “Environmental Planning for Surface Mining of Coal”, Environmental Consequences of Energy Production Problems and Prospects, ABD: The Pennsylvania Academy of Science, sf. 54.

[17] Akpınar, N. 1994. “Açık Kömür Ocaklarında Çevresel Etki Değerlendirmesi ve Doğa Onarım Çalışmalarının Milas-Sekköy Açık Kömür Ocağı Örneğinde İrdelenmesi”, Doktora tezi, Ankara: Ankara Üniv. Fen. Bil. Enst., sf. 30-42.

[18] Holmberg, G.V. 1983. "Vegetation Establishment on Abandoned Coal Mined Land”, American Society of Agricultural Engineers, Transactions: General Edition 23, ABD, sf. 117-120.

[19] Külekci, Ö. C., Belkayalı, N., 2009. Madencilik Çalışması Sonrası Onarım Sürecinde Püskürtmeli Bitkilendirme İşlemi (Hydroseeding) Kullanımı, 3. Madencilik ve Çevre Sempozyumu, s. 309-313, Ankara

[20] Cındık,Y., Acar,C. 2010. Faaliyeti Bitmiş Taş Ocaklarının Yeniden Rehabilite Edilmesi ve Doğaya Kazandırılması. Artvin Çoruh Üniversitesi Orman Fakültesi Dergisi, 11(1):11-18 (2010)

[21] Anonim, 2007. Madencilik Faaliyetleri ile Bozulan Arazilerin Doğaya Yeniden Kazandırılması Yönetmeliği, 14 Aralık 2007 tarih ve 26730 sayılı Resmi Gazete

[22] Çevresel Etki Değerlendirmesi Yönetmeliği (16 Aralık 2003) T.C. Resmi Gazete (Sayı: 25318) Erişim adresi; www.resmigazete.gov.tr/eskiler/2003/12/20031216.htm

[23] Madencilik Faaliyetleri ile Bozulan Arazilerin Doğaya Yeniden Kazandırılması Yönetmeliği (14 Aralık 2007) T.C. Resmi Gazete (Sayı:26730) Erişim adresi; www.resmigazete.gov.tr/eskiler/2007/12/20071214-5.htm

[24] Madencilik Faaliyetleri ile Bozulan Arazilerin Doğaya Yeniden Kazandırılması Yönetmeliği (23 Ocak 2010) T.C. Resmi Gazete (Say1: 27471) Erişim adresi; http://www.resmigazete.gov.tr/eskiler/2010/01/20100123-1.htm 


\section{Extended Abstract}

\section{Introduction}

Mine is defined as the minerals and elements with economic value found in the geological units which constitute the earth's crust. Mining activities include exploration of mines, preparatory works for production, production, shipment, ore preparation and enrichment, disposal of wastes, stocking / storage operations at the license site, closure of mining facilities and making all these facilities environmentally friendly and establishment of facilities related to these activities [1]. Mining activities are among the oldest sectors starting with human history. The discovery and processing of mines played important roles in the developmental stages of mankind in the history. Resulting from its geological structure, Turkey is among the countries with high mining potentials since it harbours significant amount of mine in terms of diversity and is rich in mineral resources. However, the legal framework including laws and regulations related to the environmental impacts of the mine sites could only be enacted in the last 20 years. Among the most important impacts of mining activities on environment in general are natural structure degradation, change of topography, land use changes, dust and gas emissions, solid wastes, liquid wastes, hazardous wastes, process wastes and those like the changes in the socio-economic structure of the region.

The recovery of the mining sites is a very sensitive issue. Ecological conditions should be taken into consideration together with the political, sociological and economic conditions of the mining site in order to serve the public interest and to use it in the most correct way. There is a need for at least 40-50 years to restore and recover the existing flora to its original form in the areas where mining activities are carried out if the repair work is conducted and the area is left redundant [6]. In short, the adversities that arise as a result of mining activities may vary partly depending on the structure of the natural environment and mine, the mining technique applied and the structure of the enterprise [7]. With the advancements in science and technology, the re-use of deteriorated landscapes in mining areas can be an alternative to ecological restoration. End-of-life mines can be reclaimed and recycled with appropriate planning efforts [12]. It is one of the most rational ways to recover the land to rearrange the mining areas for recreational purposes in the areas close to the city centre. In particular, the rearrangement of these areas for recreational purposes has positive effects on the social, physiological and psychological structures of individuals [13].

It is desired for a sustainable environment to manage the factors threatening nature at their sources and offer solution proposals. At this point, there is a need for the collaboration of several professional disciplines. Landscape architects, one of these occupational groups, also take part in all stages of landscape repair processes and support the sustainable environment. Landscape restoration is a healing process of deteriorated areas due to various uses which covers the removal of the damaged areas, the restoration of the area and the creation of new conditions in the area [15].

The aim of the present study is to investigate the duties and responsibilities of the members of landscape architecture occupation in the restoration of degraded lands at the beginning, in the middle and at the end of the mining activities.

\section{Method}

The material of the study is the data obtained from literature review to find out the duties of people with the tittle of Landscape Architects in the rehabilitation of degraded areas in the existing areas after the operation of the mine areas. The method of the study is the analysis, synthesis and evaluation of the data obtained through literature review on this subject.

\section{Results and Suggestions}

Landscape architects have undertaken the task of restoring and reclaiming the destroyed ecological and economic value of the damaged areas by mining activities in the rehabilitation and landscape repair work of the degraded areas. While rearranging the area it is possible not only to provide green areas by performing plantation but also produce aesthetically and visually beautiful public areas, integrate these public areas with environment and people, to offer the opportunity for the development of wildlife and food chain by itself, to make suitable the water filled shallowly - excavated points for fishery propagation and to give economic value to the area by constructing recreational areas. Landscape architects have several duties in the repair phases of the mine areas and in all stages of planning, land use design, rearrangement, improvement and monitoring - maintenance. Although the landscape architects have the competence to perform these duties with their education and experience, they are not given the importance they deserve to work on the subject. 